\title{
HAND-ARM VIBRATION MANAGEMENT: AN OPERATIONAL HEALTH AND SAFETY STRATEGY FRAMEWORK
}

\begin{abstract}
Purpose: Human vibration exposure from hand-operated equipment emissions can lead to irreparable and debilitating hand-arm vibration syndrome (HAVS). While work-place health and well-being (H\&WB) policies, strategies and procedures have been extensively researched and documented, little has been done to develop a specific strategic framework tailored to the management of hand-arm vibration (HAV). This study fills that gap.

Methodology: A mixed philosophical approach of interpretivism and critical realism is adopted within a case study of a utilities contractor. Within this overarching epistemological design, action research approach is implemented via a three-stage investigation viz: relevant company H\&WB documents and procedures were examined, leading to the formulation of semi-structured interview questioning of the H\&WB team. Their responses informed the next line of questions, delivered to middle-management responsible for overseeing H\&S.

Findings: The findings are instructive in revealing that while substantial documentation management (augmented with protocols and checks) was in place, the system fell short of implementation within the workforce and thus failed to preserve worker H\&WB. The investigation generated recommendations for shoring up H\&WB deficiencies observed and developed a theoretical model to represent these. Though these recommendations were developed in response to a specific case, they form the core of a HAV operational H\&WB strategy framework with applicability over a broader context.
\end{abstract}

Originality: This research provides unique insight into contemporary industry practices employed to manage HAV in the workplace and represents an invaluable opportunity to learn from prevailing practices and rectify deficiencies observed.

\section{KEYWORDS}

Hand-arm vibration, hand-arm vibration syndrome, health and well-bring, case study and action research.

\section{INTRODUCTION}

Occupational health and safety $(\mathrm{H} \& \mathrm{~S})$ is a primary responsibility of work-place management (Sui et al., 2018). H\&S is especially important in the construction sector where the handling and manipulation of plant and machinery expose workers to serious or fatal injury (Edwards 
et al., 2003; Edwards et al., 2019; Edwards et al., 2020). For example, the UK government's Health and Safety Executive (HSE) found that of the five major categories of fatality occurring throughout industry during the period 2014/15 to 2018/19, stuck by moving vehicle and contact with moving machinery were responsible for $19 \%$ and $8 \%$ of all fatalities respectively (cf. HSE, 2019). Across continental Europe, Eurostat (Eurostat, 2020) report that in the EU-28 countries, 3,516 and 3,552 fatalities at work were recorded in 2016 and 2017 respectively - although definitive figures on plant and machinery fatalities were not reported, a fifth of all fatalities occur within the construction sector. Similarly, during 2018, the US had 5,250 fatalities across all industries and circa $20 \%$ of these were attributable to the construction sector (US Bureau of Labor Statistics, 2019). Cumulatively, these compelling global figures illustrate that employment in the sector remains a hazardous occupation. To combat these risks, legislation provides strong incentives to keep the work-place safe (Priest, 1988). Breaches of prevailing work-place H\&S legislation can carry heavy penalties in the UK (HASWA, 1974), Australia (cf. Provan and Pryor, 2019) and other Commonwealth countries - with similar laws in effect across the developed world (Ju and Rowlinson, 2020). These penalties can apply to the company employing a worker injured on the job, the worker themselves but also site managers and/or supervisors charged with ensuring work-place safety standards are upheld (Hale and Booth, 2019).

Work-place H\&S legislation necessitates commercial public sector and private sector enterprises have a H\&S strategy (Oswald et al., 2019). All work hazards are required to be categorized and prioritized, with remediation measures effectuated (Kasperson et al., 2018). Specifically, threats must be audited, their potential impact assessed, options for reducing these threats identified, and those options evaluated according to cost and effectiveness, with a final optimal threat mitigation action plan agreed and implemented (ibid). Indeed, to enact this process, an organisation must dedicate staff to instigate and oversee the H\&S function (Kekler et al., 2019). To this end, the law requires that all high-risk work be covered by a work-place H\&S management plan (Kim et al., 2019). The plan includes specific procedures for collecting, analysing and reviewing all hazards (Martinez et al., 2020). Control measures must be implemented, with precise protocols followed where high-risk activities are undertaken (Ajayi et al., 2020). An important tenet of the plan is that it is disseminated to all, understood and followed (Edwards and Nicholas, 2002). Supervisors must have access to the plan, as they assume ultimate responsibility for safety, as will supervisors are authorized to confirm compliance and employees whose safety is being protected, and who must adhere to 
the plan - the underpinning ethos is 'shared responsibility' (cf. Pryor et al., 2019). It is not enough to develop and initiate a H\&S management plan; it must be audited and verified (Behari, 2019). The process is cyclical, with feedback used to further refine the current plan to overcome any evident deficiencies (Pain, 2018). It is desirable that this be done in-house, sometimes with outside expertise called in to undertake H\&S audits and reviews, rather than for a company to find itself with a serious accident, followed by criminal investigation (Cameron et al., 2013).

Identifying specific work-place risks is central to the H\&S strategy plan. A niche risk associated with the use and handling of vibrating equipment and tools (e.g. plate compactors, combi-hammers or tampers (cf. Edwards et al., 2003)) is hand-arm vibration (HAV) (Edwards and Holt, 2007a). HAV is a specific sub-area of H\&S that is more specifically related to health and well-being (H\&WB). This is because, when inadequately managed, or ineffectively controlled, excessive HAV exposure can lead to the development of hand-arm vibration syndrome (HAVS), a debilitating and irreversible medical condition that encompasses neurological, vascular and musculoskeletal disorders (Rimell et al., 2008). Beyond these serious human aspects, incidents of recorded HAVS may also lead to successful private prosecution of the employer from whom the HAV exposure was experienced along with punitive enforcement action and substantial fines levelled by enforcement bodies (such as the UK's Health and Safety Executive or its international equivalent). For example, a major contractor was recently fined $£ 500,000$ (UK Sterling) and ordered to pay a further $£ 195,000$ in costs following a serious HAV breach (Gerrard, 2018). The broader negative consequences of HAVS go beyond mere financial penalties and include loss of corporate reputation, permanent damage to workers' health and loss of client confidence (Smallman and John, 2001).

While much attention has been paid to a full spectrum of work-place risks (cf. Gangolells et al., 2010), no work has been undertaken to identify a tailored, effective approach to managing H\&WB with respect to HAV risk. This study adds to the existing body of knowledge on work-place H\&WB by assessing the effectiveness of a case study company's HAV risk management plan. By undertaking an audit, facilitated through document examination and semi-structured interviews, problems in the existing H\&S regime are delineated, and a more robust operational health and safety strategy framework is identified. Associated objectives are to provide a vignette of contemporary practice that serves as an illustrative example to 
guide enterprises bearing HAV risks in developing their own resilient H\&WB strategy and engender wider polemic debate on this important issue.

\section{HAND-ARM VIBRATION: AN OVERVIEW}

Extensive research within extant literature indicates that prolonged and repeated occupational exposure to HAV heightens the risk of humans developing HAVS (Palmer et al., 2002; Edwards and Holt, 2006; Edwards and Holt, 2007b) and the debilitating ailments associated with this condition (cf. Brammer et al., 1987; Edwards and Holt, 2007a; Bovenzi, 2008; Rashid et al., 2018). Here 'exposure' is a function of both the 'vibration magnitude' emitted from the tool or work process, how much of that vibration is absorbed by the hands and forearms and the 'time' duration of that exposure - so called trigger time (Notini et al., 2008). However, Edwards et al. (2020) noted that whilst the measurement of HAV is precise, the risk of being over exposed, contracting HAVS and directly associating these with occupational activities if far from an exact science. A person's life-style must also be taken into consideration because social activities (for example, gardening) can over-expose humans to vibratory work processes (e.g. lawn mowing) (Carra et al., 2019) and dietary habits can also impact upon human health. Poor dietary habits and high cholesterol and life-style choices such as smoking will leave deposits in the vascular system and increase the vulnerability of humans to develop HAVS (Kim et al., 2019). Moreover, women are biologically predisposed to certain ailments such as Reynaud's disease irrespective of exposure (Stjernbrandt et al., 2019). So at best, precise scientific measurements give an indication of risk level only.

To measure vibration exposure in the workplace, ISO 5349 parts 1 and 2 (ISO, 2001 and 2015 ) is typically used even though original equipment manufacturers (OEMs) will declare the emission values of their tools using other standards (Edwards and Holt, 2005). OEM emission data tends to vary to working environment observations because the emphasis is on repeatability of the test vis-à-vis securing a more representative reflection of working practices. This ambiguity in collating working environment observations further exacerbates the prediction of risk exposure. This is because in practice, tool maintenance, tool age and condition, the operator's grip force and even temperature can all impact upon readings acquired. Despite these limitations and variability in data or risk exposure, employers' are legally bound to ensure that HAV exposure risks are both assessed and controlled (HSE, 2012). Edwards (2006) notes that: control measures may include: maintaining the tool 
correctly; procuring low/lower vibration tools; and/or job rotation where the tool usage is shared amongst workers to lower exposure.

Within the UK, two benchmarks for controlling vibration exposure are set within the Control of Vibration at Work Regulations, 2005 (CVWR, 2005). These are: an Exposure Action Value (EAV) and Exposure Limit Value (ELV). Edwards et al. (2020) state that:

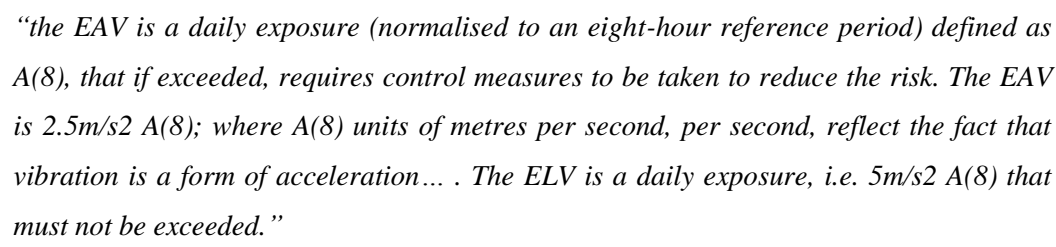

Because the calculations involved are somewhat onerous for the average construction worker, the HSE devised an equivalent points based system that enables workers to readily understand whether they are within these benchmark figures. Hence, the EAV is equivalent $100 \mathrm{HSE}$ points and the EAV is equivalent to 400 HSE points (HSE, 2019b). Practically, the points system allows an operator to simply add points accrued during each working day together to calculate their overall exposure to HAV risks. Yet, even given this simplified system, Devine (2016) suggests that operators continue to ignore control measures (or not implement them adequately) and/or fail to accurately record HAV exposure. Against this prevailing backdrop of data uncertainty, risk controls that must be adhered to under prevailing H\&S law and many contractors have sort to devise robust risk management systems that mitigate risks posed. Where such is achieved via a combination of engineering out the hazard completely (i.e. using alternative methods such as impact hammers on $360^{\circ}$ excavators to break out concrete or asphalt) and/or monitoring and controlling exposure levels (Maeda et al., 2019; Edwards et al., 2020). Whilst literature is replete with empirical research to calculate vibration exposure (Aritan, 2020), scant attention has been given to determine whether such systems are actually working in practice. Hence, underscoring the rationale for this present study.

\section{METHODOLOGY}

The overarching epistemological position adopted a mixed philosophical approach of interpretivism (cf. Roberts et al., 2018; Al-Saeed et al., 2019; Al-Saeed et al., 2020) and critical realism (cf. Bhaskar, 1975); where the latter represents a reflexive meta-theoretical 
philosophical stance that can inform future empirical investigations (Vandenberghe, 2015). Allana and Clark (2018) contend that critical realism is useful to "exploring complex interventions holistically, including their components, contexts, and mechanisms." - such $\underline{\text { attributes are relevant for the present study. } \text { - Interpretivism was adopted to contextualise }}$ extant literature to delineate upon key control measures, legal requirements and management responsibilities which formed the basis for this investigative and applied research. Such an approach has been widely adopted within construction and civil engineering management literature. For example, Nazir et al. (2020) conducted a comparative analysis of modular and traditional UK housing construction; and Spellacy et al. (2020) investigated the role of the quantity surveyor in value management workshops. This combination of philosophical positions facilitates a deeper and richer understanding of the phenomena under investigation. In a practical setting, the work was contextualised within a case study were the lead researcher was embedded as a participant action researcher (PAR) (Fisher et al., 2018). Case studies are suited to exploring complex phenomena; where the nature of the agents, and their interactions are unknown (Dixon et al., 2020). Sound case study research facilitates inductive theory building; attempting to explain how things work (Yin, 2009). PAR is implemented via a three-stage investigation using a progressive waterfall concept to codification of the qualitative analysis conducted - where the results of one stage informed the questions posed in the consecutive stage. This facilitated a thorough review of data collected and in so doing, a more exhaustive analysis than would otherwise be possible. Specifically, company H\&WB documents and procedures were examined, leading to the formulation of thematic areas of concern/further investigation and semi-structured interview questioning of the H\&WB team. Their responses informed the next line of questions, delivered to middlemanagement responsible for overseeing H\&S. Pärn and Edwards (2017) suggest that "although PAR has many progenitors, it can be broadly classed as collective selfexperimentation amongst participants that is augmented by evidential reasoning (participation), fact-finding (action) and learning (research)." From this synthesis and triangulation (cf. Edwards and Holt, 2010), new knowledge and constructive recommendations were formulated.

The case study was undertaken in strict confidentiality due to the commercially sensitive nature of the research. Consequently, specific details about participants (herein referred to as simply A, B, C, ${ }_{n}$ ), the company and timings of the investigation could not be disclosed other than generic description viz.: the company operated in the utilities sector. The company
Formatted: Font: Not Italic

Formatted: Font: Italic

Formatted: Font: Italic 
utilises numerous types of vibrating equipment for break-out and reinstatement works (e.g. plate compactors, floor saws, hand-held disc cutters, vibration tampers, and pneumatic and hydraulic breakers) and sought to optimise the management of $\mathrm{H} \& W B$ of operatives. An initial audit was conducted over a four-month period. Given that the H\&WB regime was driven by personnel (based on policy and procedures), HAV safety documentation was first examined in preparation to interviewing relevant personnel. The company made both the safety team and safety management available for interview. Six themes on training and four on general H\&S were initially developed from literature to guide semi-structured interviews held with the safety team (e.g. the health and safety manager, plant and machinery manager, two assistant health and safety managers and four regional safety representatives - all with a minimum of five years' experience in their current role). Their responses identified nine further themes for semi-structured interviews of middle-management (e.g. four contracts managers, two senior human resource managers, one quality control manager, one senior engineer and three $H \& S$ team leaders). Subsequently, telephone interviews were also made to clarify any points raised during interviews and five field visits undertaken to observe process implementation on site. All interviews were recorded with the company's consent and individuals involved to ensure fidelity of reported results.

\section{INTERVIEW FINDINGS FROM THE SAFETY MANAGEMENT TEAM}

Drawing on the literature, and through preliminary discussions with senior managers of the case company, along with an examination of the company's current safety material and policies, it is evident that operator training and competence is critical to HAV safety management. Consequently, six training related interview themes were determined: 1) communication; 2) training content; 3) timing of training; 4) knowledge assessment; 5) competence assessment; and 6) training records management. This was followed by four general tools and equipment H\&S themes viz: 7) repair and maintenance; 8) health surveillance; 9) vibration data, and; 10) equipment monitoring. Given the extensive content collected, only a small representative sample is reproduced here.

\section{Communication}

When asked about training, interviewee A said: "We have given presentations at three levels of the business, from executives, to site managers and operators - so we have tried to be holistic and make sure that everyone is informed about the risk." Respondent B added: "We also have our own training department who provide specific practical training on the tool for 
workers and this covers $H A V$." At face value, it appeared that a solid communication process for HAV training was in place.

\section{Training content}

When asked about training, interviewee B said: “...we don't go into any depth about tool selection and we simply explain that from centre (plant and logistics), that we know that you have problems with tools and that you don't always like what you get but we are working on improving these continuously." Interviewee F added: "There is more we could do here but it is work in progress." Supplying tools but not explaining the selection process, does not provide the operator with the ability to choose the right tool for the job, one that is most productive or with the least vibration. When details were probed further, interviewee A said: "We talk about actually using equipment and we call it white knuckle - you don't have to apply force from your body as the tool should do the work. We also talk about the hazards such as bad circulation and people who have to undo their gripped fingers manually because they have been gripping too tightly. We talk about keeping the circulation going." Importantly, there was no mention that gripping the tool too tightly can result in the operator absorbing more vibration energy; thereby exacerbating the risks posed (Edwards et al., 2020). Similarly, the training did not cover the inherent relationship that exists between productivity performance, vibration magnitude and ultimately, vibration exposure.

\section{Timing of training}

Interviewees were unaware of training duration, with disagreement in the discussion. Interviewee D said: "We tend to tweak training packages to the different contracts...." And interviewee G stated "There is inconsistency in approach." An assessment of these (and other similar) statements indicated that training largely represents tool box talks, with some inconsistency across training provisions.

\section{Knowledge assessment}

The audit revealed that there was no formal assessment of knowledge retention on any of the training courses administered. Interviewee C said: “We don't actually measure knowledge although we did think about asking employees to complete a few calculations ... and we do have some on-line courses." Interviewee $\mathrm{H}$ further commented that; "In this sector, time is money particularly for our subbies - it's all about laying pipe.” Therefore, there is no proof of knowledge retained or post training needs analysis. 


\section{Competence assessment}

The terms 'training' and 'competence' are distinct in their meaning. The former refers to the process by which an operative learns and acquires skills, while the later refers to a standard with which the acquired skill is executed. The interviewees however, used these terms interchangeably. Interviewee B said: "I'm not too sure on what the competency process is and would need to speak to the training department." Interviewee A reinforced this view and said: "I tried to look for some training procedures and how we manage it and I couldn't find anything." A disconnect between the health and safety, plant, training and operations departments within middle management is apparent, each department acts largely in isolation to each other. Interviewee $\mathrm{C}$ said: "That's one of the main problems we have, we can identify problems from the plant and safety departments and try to roll it out, we know what should be happening. It's trying to get that support from the rest of business that needs to be involved in it. Everyone is so set in their own ways and doing their own thing. "'

Interviewee A added: "Everything we look at seems as though we have to start from the beginning...” Respondent B said: “We're hitting walls all the time on training - we've tried to deliver this training across the business over a short spell of time and contracts are very reluctant to keep dropping men out of work... Their approach is to cram them in and get them out as quickly as possible and tick the box. Anyone they can get away without training they will do." Interviewee G said: "The industry is still very focused on production and clients' squeeze on costs and profits is unrelenting - they want the best job for no money. So training budgets are the first to cut."

\section{Training records management}

Training records management is an integral part of any risk control measure because it has the inherent capability to determine an organisation's training and competence needs. When asked about provisions to support training records management, interviewee B said: "With the new system currently being implemented, in the future, all operatives will be trained and competent... I would expect to start to see changes being made now. This is a significant change for the business." Interviewee $\mathrm{H}$ added: “Apparently a new IT system is going to be released but I haven't seen the details yet." Thus, it appears the company has acknowledged that training records management must be augmented and is taking appropriate measures to address this. 


\section{Repair, maintenance and inspection regimes}

Repair, maintenance and inspection regimes seemed comprehensive, but there were integration problems with suppliers and contractors. Interviewee E (a plant engineer) said:

"The business has progressively adopted a partnering approach with preferred hire suppliers but there have been occasions when I wonder whether their policies are as robust as ours or whether we could learn something more from them. This is on-going [work to enhance the partnership] and we do need to work even closer together in the future. We should agree a common standard and make sure we enforce it." Interviewee F inadvertently added: "The hirer sorts that out for us so we don't have to bother." Interviewee H said: "Hire machines are used and abused - I'm concerned supervisors are not checking machine maintenance is carried out." It was clear that maintenance (both daily and periodic) checks were either not completed, completed as a mere tick box exercise or in the case of Interviewee F, ambivalent to their legal responsibilities.

\section{Health surveillance records and monitoring}

Maintaining comprehensive health surveillance records is the foundation of any reliable HAV management system, since it enables the company to regularly monitor possible adverse effects resulting from HAV exposure and implement mitigating controls before serious health problems manifest. Access to records however, were unavailable, as interviewee D noted: "We have no access to health records..." and Interviewee A added "Health surveillance is subcontracted out to an external provider - it would be better if we had control in-house." So health surveillance is available but not accessible or instantly accessible to employees; such an approach may hinder the company developing in-house knowledge management as a learning organisation.

\section{Vibration data}

Almost all parties within middle management believed that more attention should be given to obtaining credible and accurate vibration magnitude data. Interviewee F said: "I don't think that we're carrying out vibration monitoring correctly because we're using manufacturer figures which could be miles out. So, the measurements we have on paper look as though we have the problem under control when in fact we don't." However, vibration magnitude is only part of the vibration exposure issue and consideration must also be given to productivity performance of tools used. Moreover, vibration emission testing can produce inherently 
variable data (caused by factors including age and condition of the tool, temperature, grip force, feed force etc.) and hence, investing a disproportionate amount of time trying to identify the most accurate reading may be misdirected.

\section{Equipment monitoring}

From interviews conducted, it appeared that limited attention had been paid to formally assessing the productivity performance of machines operating on site. Nor had the appendages (drill bits, diamond blades, etc.) fitted to the tools been assessed - yet appendages can have a considerable impact upon machine/tool performance (cf. Edwards, 2006). The root cause of this problem is exemplified by Interviewee A, who said: "I don't really know a lot about plant and machinery and have had to pick up a lot as I have gone along. This job was given to me to do and so I've done my best to complete the work [on HAV management] - if the truth be known, I wasn't very confident of doing this job."

\section{INTERVIEW FINDINGS FROM MIDDLE MANAGEMENT TEAM}

While equipment operators and the safety team bear the front-line responsibility for safety outcomes, their effectiveness in that role is constrained by the level of support provided by the case company and its management. From the first round of interviews with the safety team, it was determined that management support may not be at the level conducive to promote a satisfactory safety environment. Consequently, nine further interview themes were developed for mid-management: 1) management training; 2) operative training; 3) policy development and process implementation; 4) HAV data management; 5) HAV data; 6) tool replacement; 7) tool procurement; 8) records management and; 9) problems identified by staff. A precise of the key interview findings across these themes, follows.

\section{Management training}

A concerted effort had been made to ensure that a broad knowledge of HAV awareness was integrated throughout all levels of the company. For example, back office staff had received training so that administrators were aware of the paperwork completed, and why and how to store related documentation. Similarly, senior manager training had also been provided. Interviewee MC said: "It [training materials] goes to senior management teams on each contract - so you've got your lead which would be your director or operations manager, contracts managers, project managers... Site managers have a really strong role in managing vibration at work because it's site managers out on site so the training given is at a very high 
level and details what site managers should do - it's really aimed at executives to let them know that we will be speaking to site managers and to let them know what is expected." When pressed however, the deficiencies in the training became apparent. Interviewee MC continued: "We've tried to keep the training as simple as possible as it's a very complicated subject ... that we haven't rolled out across the entire business - and we've tried to keep it simple so that the workforce don't have to do calculations on site."

\section{Operative training}

Discussions with almost all respondents revealed that not all workers were trained. Interviewee MA gave a specific example viz.: “We came across this lack of training on twoman gangs where one man was using the equipment all day and said that he couldn't rotate the task because he was the only man trained. The contracts team doesn't see the need to train the other employee. This contradicts one of our basic risk control measures - which is to encourage sharing of the task/job rotation or even introducing an extra trained man into the team. All training is paid for through the contract budget and although training is patchy across contracts, we are trying to encourage it but again it's down to contracts not us [in the health and safety department]."

\section{Policy development and process implementation}

Interviews with members of the H\&S team suggested that although new occupational health and safety policies had been developed, these were often not adhered to by the operations department. Interviewee MF said: "The problem we have is that the health and safety team develop policies and just hand them over to the operations department to work out how a process should be implemented. What we really need is more joined up thinking on common issues and team working on policy development and process implementation."

\section{HAV data management}

HAV data management is a prerequisite component of a safe system of work - however, it can be cumbersome to manage and it is no substitute for broader effective risk control measures. Interviewee MC said: “Although we have adopted a paper based system which is a bit prehistoric, we do talk about the various systems out there that can automatically monitor for HAV exposure, like the [company name omitted] system, and the problems and issues we've had with these systems when we've looked into implementing these systems. There are big cost problems and you have to download reports that someone has to read, and then 
interpret the data. Some of the contracts want to use what they see as being an automated system and they don't want to fill out paperwork so we advise that if you have the budget then trial them by all means but that is not something that would be rolled out from a central function." When quizzed about whether data was being entered into the system, Interviewee MA said: "I don't know." Such responses raise concerns about the management of HAV data and the level of knowledge to be accrued from such.

\section{HAV data}

Sourcing reliable vibration magnitude data is an important aspect of an overall risk control system. Such data is broadly classified into two dichotomous groups, namely: i) in-use data which includes data produced via on site or simulated real work assessment to ISO5349; and ii) original equipment manufacturer (OEM) emission data. Generally, in-use data is understood to produce higher readings due to the variation in variables, such as materials, when in use. For example, research has revealed that vibration readings for an average in-use combi-hammer can range anywhere between $12 \mathrm{~m} / \mathrm{s}^{2}$ and $25 \mathrm{~m} / \mathrm{s}^{2}$ (Edwards, 2006). OEM data, on the other hand, are specifically designed to be more repeatable and less open to variation; this then allows OEMs to compare their tools against competitors. A point to note is that both in-use testing to ISO 5349 parts 1 and 2 and OEM testing standards require that a mean value, and standard deviation about this mean, be recorded to provide the average emission as acceleration in $\mathrm{m} / \mathrm{s}^{2}$. Accepted best practice indicates that the standard deviation is then added to the mean to give a value in the upper quartile range, thus ensuring that this resulting value provides a built-in factor of safety for risk control purposes. Interviewees were unaware of this. Regarding OEM data, interviewee MA said: "This is the only consistent data we could get."

\section{Tool replacement}

When asked about measures to replace high vibration emitting tools (on the in-house equipment register), interviewee ME said: “It's an on-going process. The register is continuously being reviewed and some items have been removed over the past couple of months." Examination of the register itself revealed however, that only vibration magnitudes are reported, and no account had been made for the productivity performance or trigger time of hand held tools. Consideration of productivity performance means that 'higher productivity tools', with 'higher vibration emission' could actually produce a 'lower vibration exposure' for the operator when compared to similar tools with 'lower productivity' and 'lower 
vibration emission'. In the absence, of complete information the opportunity to better manage the risk posed is lost.

\section{Tool procurement}

With regard to tool procurement, interviewee MB reassuringly said: "On our approved list of tools we consider noise, weight and vibration and we complete an assessment when we bring a new product in... so there is a trade-off between these safety considerations. In our new procedure we shouldn't be bringing any new tools into the business unless better or the same as what we already have [in terms of vibration performance]." However, there appeared to be no strategy for appendages procurement (despite the impact [negative or positive] upon a tools vibration output), albeit respondents claimed that they were currently looking into this. Moreover, Interviewee MG said: "A major weakness is that operations directors are sometimes a law unto themselves and allow subbies to use tools that not approved - as long as the job gets done."

\section{Records management}

When asked about records management and risk controls interviewees indicated that processes were being followed, but loosely. Interviewee MB said: "At present we ask people to go to 100 points and then stop but what we should really be doing is to say plan the job before we start so that you make sure that operatives never go over 100 points. Interviewee MG said: "Worker culture is improving and this is key - choosing the right machine for the job and maintaining it correctly. On some of the contracts our subbies might not use the machines we recommend on our inventory." Cumulatively, the findings illustrate that a more simplified records management approach is sought but there were some areas of inconsistency - particularly for subcontractors.

\section{Problems identified by staff}

Towards the end of the interviews, all respondents began to open up about their genuine fears and concerns as their confidence and trust grew with the researchers. Interviewee MA said: "We need to keep records of exposures in the workplace, need to raise awareness throughout the workforce as to what these points mean and why we need to take action. Sometimes it feels as though, in some parts of the business, we tell people to implement plans to protect their own health and they just write numbers down willy-nilly without understanding the importance of these numbers and what it means to their health..." 


\section{SUMMARY OF MAJOR FINDINGS}

The current vibration process safety management regime and corresponding spans of control are identified as shown in Figure 1. The operational hierarchy consists of four tiers: 1) site operative; 2) site manager; 3) safety advisor, and; 4) central health and safety (H\&S) and plant departments. The reporting function moves from the site operative, through the tiers, to central H\&S. Records kept by the site manager are inspected monthly by the safety advisor. Similarly, feedback and control mechanisms move in reverse, from central H\&S to the site operative. The H\&S role is to provide guidance and support to the safety advisor.

\section{$<$ Insert Figure 1 about here>}

From a process, system and procedural perspective, HAV management within the case company appears 'at face value' robust. However, examination below this layer through the two-tiered interview process reveals significant gaps in practice within the middle and lower level tiers. Interviews reveal that HAV reports are fed into the upper tier management structure and consequently, HAV policy and practice has undergone continual development and improvement. Nevertheless, this development has obscured an undercurrent of frustration and division between the various departments in middle management who have been championed to implement this change. The core problem is that middle management leadership is weak, being ineffective at moving the company's safety policies into full operation. This engenders major repercussions on the implementation of safe and healthy systems of working in practice. Notably, the organisational structure itself may propagate this division, with each department pursuing separate agendas at any given time - a notable lack of collegiate coalescence is glaringly apparent. The interview process also identified remedial actions. The consensus of opinion was that management must synergise and focus H\&S efforts within, and between, the departments. This would assist in hastening the pace of HAV management reform and act as an effective conduit of communication to upper tier management. In synthesising both the problems identified and suggestions for improvement, two major outcomes are indicated. These are a revision of the HAV H\&S policy architecture, based on a comprehensive audit of workplace vibration exposure. Both the improved HAV $\mathrm{H} \& \mathrm{~S}$ policy framework and the work study audit, are discussed in the following section.

\section{DISCUSSION}


This case study highlights an oft cited observation that, despite best intentions and efforts, $\mathrm{H} \& \mathrm{~S}$ systems can fall short of requirements. Reviewing the case safety documents and procedures, followed by interviews with key safety personnel and responsible middlemanagement, revealed numerous areas of failing. Considering these observations, an operational HAV H\&S strategy framework can be developed and implemented. At minimum, it would better serve the case study company's H\&S needs but the findings presented here are expected to have wide applicability to any firm obviating the risk of HAVS arising from its enterprise activities. The strategy framework comprises two parts, as shown in Figure 2. First, a policy architecture is developed to capture the critical issues that must be addressed. Subsequently, a feedback loop is developed to ensure that appropriate data is fed into the policy framework such that timely and effective procedures, checks, reporting and codes of conduct are initiated.

\section{<Insert Figure 2 about here>}

\section{Proposed HAV H\&S policy architecture}

The case examination revealed on one hand, a continual process of development and improvement for HAV management and on the other, systemic failures within middle management to effectively deliver a safe system of work for managing HAV in practice. At this tier, individual managers and departments act autonomously, rarely genuinely collaborate, and at times, blame each other for failings in practice. The present organisational structure, which partitions responsibility, has created division and semi-autonomy. This, combined with a management culture unwilling to take responsibility, has exacerbated the problem. Diffusion of roles and responsibilities has unwittingly created barriers to improving worker health on site. Pockets of excellence in practice were cited by respondents but this is the exception rather than the rule, and not uniform across the company. Considering the issues reported by interviewees, a number of recommendations present themselves as practical improvements moving forward. Pooling these together into five themes, an overarching policy doctrine is developed. These five policy themes cover five broad management functions viz.: 1) training and competence; 2) records management; 3) single point of responsibility; 4) data sources, and; 5) equipment procurement and maintenance. These themes are critical to an effective operational H\&WB strategy and must be informed and updated by site practices in a virtuous control loop; where management 'input feed' (i.e. what management believe to be ideal solutions) inform site practices and site practices 'output feed' (i.e. what occurs in practice) influence management thinking. In particular, it is indicated that 
an operational implementation programme be initiated, and that specific individuals be assigned responsibility for design and completion of the H\&WB strategy according to the policy framework (to monitor H\&WB control activities in the work-place and throughout management). Figure 3 presents the five-point policy framework.

\section{<Insert Figure 3 about here>}

\section{Training and competence}

Training for operatives and site managers is a critical risk control measure (Edwards, 2006). The recommendations for training developed out of the case study, are to:

- Improve content coverage on tool and appendage selection within classroom-based training materials, not just via practical demonstrations;

- Increase training duration to include applied examples of tool usage 'trigger' times, job rotation and other practical risk control measures;

- Explicitly state how the risks are managed, complemented with real life scenario case studies of systems and processes;

- Include detailed guidance from OEMs on specific tool usage, handling, maintenance and inspection;

- Follow National Occupational Standards (NOS) and for all future training to be developed using the established Mellor Loop technique for developing training content (cf. Edwards, 2003).

- Afford greater attention to issues such as grip force, feed force, posture and how these risks are mitigated;

- Demonstrate the relationship between vibration magnitude and productivity performance during classroom and practical sessions; showing, for example, where higher vibrating tool may give a lower exposure if task is completed more quickly;

- Include a formal knowledge assessment post a training session, and issue an in-house certificate to increase the perceived value of the training; and

- $\quad$ Provide periodic competence assessment for all operatives on-site using pro-forma guidance that is supported by photographic evidence, where applicable.

\section{Records management}


Whilst conducting the interviews, it was apparent that significant progress was being made to improve data capture and records management, yet when requested, information was not immediately forthcoming or could not be located. Consequently, the following recommendations are made:

- All training should be recorded using a training needs analysis matrix whereby individual items on the matrix are mapped against an individual's job roles and responsibilities. Training records management should be able to identify a historical audit as well as provide guidance for future training provisions, at the same time providing proof of satisfying regulatory obligations;

- All training materials should be readily available, and communicated to all management staff, regardless of which department they belong to. As an absolute minimum requirement, training, health and safety, plant and operations departments should all have readily available and complete access to training records (within the bounds of confidentiality).

- All essential HAV management information and documentation, comprising practical case studies of best practice, HAV data, health surveillance, risk assessments and information from any work studies conducted (see below), should be complete and held on one single database. The aim should be to establish a community of best practice 'portal' centrally within the organisation that is accessed by all but managed, controlled and maintained by a single individual and/or team.

\section{Single point responsibility}

Given the observed fragmented co-ordination between departments, it is recommended that a position with single point responsibility for HAV management be created (such a position may encompass other related H\&WB concerns such as noise, dust etc.). The position would be granted authority and the responsibility to liaise between directors, middle management and the workforce to ensure that plans initiated are effectively implemented in practice.

\section{Data sources}

It is recommended that OEMs' declared standard deviation and the mean average emission value (in $\mathrm{m} / \mathrm{s}^{2}$ ) for each tool are summed to produce values that are inherently safer since they sit at the $68 \%$ percentile range of emission for that tool. Such a value is indicative of risk only 
and far greater attention must be given to controlling the risk posed through effective risk mitigation measures employed (e.g. designing out the need for tool use, job rotation or procuring the lowest vibrating tool).

\section{Procurement and maintenance}

Any loopholes that permit unauthorised to procure a tool or appendage, should be immediately closed, while a detailed review of current procurement processes is undertaken. All tools and appendages must be checked to their entry on a central inventory and that all salient information such as age, periodic servicing, parts replaced etc., are contained within this. In addition, all high vibration tools used should be removed from service as they are inherently dangerous and should not be used under any circumstance.

\section{Work study feedback loop}

For the policy architecture to be effective, it must be supported by accurate and relevant input data. With respect to HAVS, the critical question is how much exposure to vibration can be tolerated without developing health concerns. Tools generating minimal vibration are to be preferred, as are work practices requiring minimal use of vibrating tools. Field studies are required to measure both the productivity performance of key work activities and the cumulative power tools used so that a more robust estimate of 'vibration exposure' can be determined per work activity. Such studies should maintain focus upon the task being undertaken, which may involve the use of a range of tools, as this will identify:

- Typical vibration exposures for common workplace activities;

- High, medium and low risk vibration exposure activities as a means of risk categorisation and subsequent development of robust risk control measures for these. This will also serve to reduce the associated paperwork required for low-medium risk activities (e.g. daily exposure sheets completed by the workforce) because such risks may require periodic as opposed to continual monitoring;

- The risks to be assessed, along with control measures to be planned, before works commence. This could readily be achieved via the development and use of a simple risk control calculator;

- Which high risk activities require either a change in working practices or the implementation of other risk mitigation strategies; and 
- A far more pragmatic approach to controlling HAV risks within the business. The emphasis should be on practical, user friendly information that can readily be utilised by all with minimum effort.

Figure 4 illustrates a five-stage procedure for conducting the field data study.

\section{<Insert Figure 4 about here>}

Stage 1 - Vibration magnitude data $\left(\mathrm{m} / \mathrm{s}^{2}\right)$ for tools used (owned and hired) are identified and these data are categorised into high, medium and low risk using $\geq 5 \mathrm{~m} / \mathrm{s}^{2} ; \geq 2.5 \mathrm{~m} / \mathrm{s}^{2} \leq 5 \mathrm{~m} / \mathrm{s}^{2}$; and $\leq 2.5 \mathrm{~m} / \mathrm{s}^{2}$ band widths respectively, Note that such categorisation represents an initial estimate until the results of Stage 3 are confirmed (refer below). Common work activities must then be determined and tools used identified. These tools, together with their vibration magnitudes, are then used to categorise high, medium and low risk activities using band width categories.

Stage 2 - Next, a random sample of high, medium and low risk activities are selected from the population of all work activities. This sample is stratified by contracts to enable comparisons to be made post data collection. Ideally, a minimum sample size of $\geq 200$ should be selected to enable robust analysis, providing suitable confidence in the findings.

Stage 3 - Time and motion studies should be conducted to record both tools' trigger times and productivity performance rates in order to record vibration exposure data. Such data will allow a far greater estimate of vibration risk than by using mere vibration magnitudes alone (as first recorded in Stage 1).

Stage 4 - Using vibration exposure values (obtained from Stage 3), the band width categories for work activity (Stage 2) are revised to more accurately reflect the risks posed. Based upon the results of this work, mitigating risk control measures can then be taken to effectively reduce the risks posed by all work activities studied. This approach may also identify lower risk activities where the need for periodic or continuous monitoring of vibration exposure, either via manual recording of electronic means, is reduced significantly; and hence, HAV data management bureaucracy is minimised.

Stage 5 - Stages 1 to 5 should be repeated periodically, in order to ascertain the success of strategies implemented, and thereby identify where further improvements can be made, and where risks can be reduced further. 


\section{CONCLUSION}

Injury from hand-arm vibration (HAV) is a niche risk within the gamut of occupational health and safety risks. Equipment generating excessive degrees of vibration combined with users operating such equipment for extended periods, can lead to debilitating and non-reversible neurological, vascular and musculoskeletal disorders. Managing and mitigating HAV injury can be undertaken within broader enterprise $\mathrm{OH} \& \mathrm{~S}$ strategies. Nevertheless, HAV risks exhibit unique properties that warrant targeted interventions if occupational safety is to be optimized. Specifically, activities requiring use of vibrating equipment must be identified, along with duration of task usages, magnitude of vibration, and diagnoses of outcomes and determinations of safe vibration exposure. Moreover, data collection, analysis, and reporting, must also be undertaken in order to develop HAV safety policy, and to implement it effectively.

While enterprises that utilize vibrating equipment in the course of their activities can be expected to conform to legislated health and safety requirements, no independent, systematic study has yet been undertaken to audit the effectiveness of extant company HAV policies and practices. This study fills that need. Access was granted to a major UK utility company to assess the firms' HAV safety protocols. Though the firm took its H\&S responsibilities seriously, with fully developed systems and policies in place, significant deficiencies were found. Through extensive interviews of management and safety personnel, along with a careful review of company procedures, failure, broadly, was found to lie in the imperfect transition of policy into practice. In responding to this safety failure, an HAV H\&WB strategy framework is proposed. It comprises a policy architecture emphasising five critical elements, supported by a recommended five step data feedback loop, designed to supply the required data input on which the success of the H\&S policy rests. While the H\&WB strategy framework was developed in response to the specific case conditions encountered in this study, the resulting framework is expected to be applicable across settings where firms require management of HAV risk. The validation of the robustness of the proposed strategy framework is yet to be tested in subsequent research.

Finally, it should be noted that whilst every effort was made to conduct a scientific, qualitative research study free of bias, the research design scope limited the interviews to mostly members of the health and safety and middle management teams. A wider sample, incorporating equipment users, and senior management (director) may have garnered 
additional insight. Moreover, the study was limited to a single company, and thus applicability of the conclusions derived to the wider community and industry at large, remains subject to the usual reservations inherent to case study research. As previously mentioned, a follow-up study is envisioned in which recommendations made here are expected to be implemented, and then assessed for their effectiveness in lifting HAV H\&WB outcomes. This follow-up study is anticipated to test validation of the health and safety strategy framework proposed here.

\section{REFERENCES}

Allana, S. and Clark, A. (2018) Applying meta-theory to qualitative and mixed-methods research: a discussion of critical realism and heart failure disease management interventions research, International Journal of Qualitative Methods, Vol. 17, No. 1. DOI: https://doi.org/10.1177/1609406918790042

Al-Saeed, Y., Pärn, E.A., Edwards, D.J. and Scaysbrook, S. (2019) A conceptual framework for utilising bim digital objects (bdo) in manufacturing design and production: a case study. Journal of Engineering Design and Technology. Vol. 17 No. 5, pp. 960-984 DOI: https://doi.org/10.1108/JEDT-03-2019-0065

Al-Saeed, Y., Edwards, D. and Scaysbrook, S. (2020) Automating construction manufacturing procedures using BIM digital objects (BDOs): Case study of knowledge transfer partnership project in UK, Construction Innovation, Vol. ahead-of-print No. ahead-of-print. DOI: https://doi.org/10.1108/CI-12-2019-0141

Ajayi, A., Oyedele, L., Akinade, O., Bilal, M., Owolabi, H., Akanbi, L. and Delgado, J.M.D. (2020) Optimised big data analytics for health and safety hazards prediction in power infrastructure operations, Safety Science, Vol. 125. DOI: https://doi.org/10.1016/j.ssci.2020.104656

Aritan, A.E. (2020) Investigation of Correlation of Excavator Operators' Hand-Arm Vibration Exposure with Produced Rock Physical-Mechanical Properties in Natural Stone Quarries. Mining, Metallurgy \& Exploration Vol. 37, pp. 231-238. DOI: https://doi.org/10.1007/s42461-019-00159-8

Bhaskar, R. (2008) A Realist Theory of Science. Routledge, Oxon. ISBN-13: 978-0-20389263-3

Behari, N. (2019) Assessing process safety culture maturity for specialty gas operations: A case study, Process Safety and Environmental Protection, Vol. 123, pp. 1-10. DOI: https://doi.org/10.1016/j.psep.2018.12.012 
Bovenzi, M. (2008) A follow up study of vascular disorders in vibration-exposed forestry workers, International Archives of Occupational and Environmental Health, Vol. 81, No. 4, pp 401-408. DOI: https://doi.org/10.1007/s00420-007-0225-9

Brammer, A.J., Taylor, W. and Lundborg, G. (1987) Sensorineural stages of the hand-arm vibration syndrome, Scandinavian Journal of Work, Environment and Health, Vol. 13, No. 4, pp. 279-283. Stockholm Workshop 86: Symptomatology and diagnostic methods in the hand-arm vibration syndrome: Hässelby Castle, Stockholm, 21-23 May 1986.

Cameron, I., Hare, B. and Duff, R. (2013) An analysis of safety advisor roles and site safety performance, Engineering, Construction and Architectural Management, Vol. 20, No. 5, pp. 505-521. DOI: https://doi.org/10.1108/ECAM-01-2012-0002

Carra, S., Monica, L. and Vignali, G. (2019) Reduction of workers' hand-arm vibration exposure through optimal machine design: AHP methodology applied to a case study, Safety Science, Vol. 120, pp. 706-727. DOI: https://doi.org/10.1016/j.ssci.2019.07.034.

CVWR (2005) The Control of Vibration at Work Regulations 2005, Statutory Instrument No. 2005 1093, London, UK: Crown Copyright. Available via: http://www.legislation.gov.uk/uksi/2005/1093/contents/made [Accessed: April, 2019].

Devine, R. (2016) Hand-arm vibration exposure in warm climates: promoting awareness of health effects and controls to employees, management and contractors, Acoustics Australia, Vol. 44, No. 1, pp. 107-1112. https://doi.org/10.1007/s40857-015-0033-4

Dixon, C., Edwards, D.J., Lai, H.K., Garcia-Mateo, M., Thwala, W.D., and Shelbourne, M. (2020) An investigation into the erroneous access and egress behaviours of building users and their impact upon building performance. Facilities, Vol. 38, No. 9/10, pp. 739-760. DOI: https://doi.org/10.1108/F-05-2019-0053

Edwards, D. J. and Nicholas, J. (2002) The state of health and safety in the UK construction industry with a focus on plant operators, Structural Survey, Vol. 20, No. 2, pp. 78-87. DOI: https://doi.org/10.1108/02630800210433855

Edwards, D. J. (2003) A best practice guide for plant instructors. Off-highway Plant and Equipment Research Centre. ISBN 0-947974-14-8

Edwards, D. J., Harris, F. C. and McCaffer, R. (2003) Management of off-highway plant and equipment. London: Spon. ISBN: 0-415-25127-3

Edwards, D.J. and Holt, G.D. (2005) Exposure to hand-arm vibration: implications of new statutory requirements. Building Research and Information, Vol. 33, No. 3, pp. 257-66. DOI: https://doi.org/10.1080/09613210500082552 
Edwards, D.J. (2006) Hand-arm vibration, OPERC health and safety study module OPERC-

SM-009, Version 2. OPERC: Dudley, UK. Available via: https://www.operc.com/downloads/Bookshop/SM-009-HAV-a.pdf [Accessed: May, 2019].

Edwards, D.J. and Holt, G.D. (2006) Hand-arm vibration exposure from construction tools: results of a field study, Construction Management and Economics, Vol. 24, No. 2, pp. 209-217. DOI: http://dx.doi.org/10.1080/01446190500310643

Edwards, D. J. and Holt, G. D. (2007a) A guide to hand-arm vibration. 2nd edn. Off-highway Plant and Equipment Research Centre, Dudley. ISBN: 978-0-947974-54-1

Edwards, D.J. and Holt, G.D. (2007b) Perceptions of workplace vibration hazards among a small sample of UK construction professionals, Engineering, Construction and Architectural Management, Vol. 14, No. 3, pp. 261-276. DOI: http://dx.doi.org/10.1108/09699980710744908

Edwards, D. J. and Holt, G. D. (2010) The case for '3D triangulation' when applied to construction management research. Construction Innovation, 10(1), pp. 25-41. DOI: https://doi.org/10.1108/14714171011018292

Edwards, D. J., Pärn, E. A., Sing, C. P. and Thwala, W.D. (2019) Risk of excavators overturning: determining horizontal centrifugal force when slewing freely suspended loads, Engineering, Construction and Architectural Management, Vol. 26, No. 3, pp. 479-498. DOI: https://doi.org/10.1108/ECAM-03-2018-0125

Edwards, D.J., Rillie, I., Chileshe, N. Lai, J., Hossieni , M. Reza, and Thwala, W.D. (2020) A field survey of hand-arm vibration exposure in the UK utilities sector, Engineering, Construction and Architectural Management. Vol. Ahead of Print. DOI: https://doi.org/10.1108/ECAM-09-2019-0518

Eurostat (2020) Accidents at work statistics, European Commission website, Brussels. Available via: https://ec.europa.eu/eurostat/statisticsexplained/index.php/Accidents_at_work_statistics [Accessed: June 2020].

Fisher, L., Edwards, D. J., Pärn, E. A. and Aigbavboa, C. O. (2018) Building design for people with dementia: a case study of a UK care home. Facilities, 36(7/8), pp. 349-368. DOI:10.1108/F-06-2017-0062

Gangolells, M., Casals, M., Forcada, N., Roca, X. and Fuertes, A. (2010) Mitigating construction safety risks using prevention through design, Journal of Safety Research, Vol. 41, No. 2, pp. 107-122. DOI: https://doi.org/10.1016/j.jsr.2009.10.007 
Gerrard, N. (2018) Balfour Beatty hit with £500,000 HAVS fine, Construction Manager,

Chartered Institute of Building (CIOB), Available via: https://www.constructionmanagermagazine.com/balfour-beatty-hit-500000-havs-fine/

[Accessed: June 2020).

Hale, A and Booth, R. (2019) The safety professional in the UK: Development of a key player in occupational health and safety, Safety Science, Vol. 118, pp. 76-87. DOI: https://doi.org/10.1016/j.ssci.2019.04.015

HSWA (1974) Health and safety at work etc. Act 1974, UK Government, London. Available via: http://www.legislation.gov.uk/ukpga/1974/37/contents [Accessed: June 2020].

HSE (2012) Hand-arm vibration at work: A brief guide, INDG175(rev3), London, UK: HSE Publications, Crown Copyright. Available via: http://www.hse.gov.uk/pubns/indg175.pdf [Accessed: May, 2019].

HSE (2019) Kinds of accident statistics in Great Britain 2019, Health and Safety Executive, London. Available via: https://www.hse.gov.uk/Statistics/causinj/kinds-of-accident.pdf [Accessed: July, 2020].

ISO (2001) International Standards Organisation ISO 5349-1: 2001. Mechanical vibration Measurement and evaluation of human exposure to hand-transmitted vibration - Part 1: General requirements, ISO Copyright Office, Geneva, Switzerland

ISO (2015) British Standard BS EN ISO ISO 5349-2:2001/Amd 1:2015. Mechanical vibration - Measurement and evaluation of human exposure to hand-transmitted vibration - Part 2: Practical guidance for measurement at the workplace AMENDMENT 1, ISO Copyright Office, Geneva, Switzerland

Ju, C. and Rowlinson, S. (2020) The evolution of safety legislation in Hong Kong: Actors, structures and institutions, Safety Science, Vol. 124, DOI: https://doi.org/10.1016/j.ssci.2020.104606

Kasperson, R.E., Kasperson, J.X., Hohenemser, E., Kates, R.W. and Svenson, O. (2018) Corporate management of health and safety hazards: a comparison of current practice, Routledge, Oxon. ISBN-13: 978-0-367-01284-7

Keckler, M.S., Anderson, K., McAllister, S., Rasheed, J.K. and Noble-Wang, J. (2019) Development and implementation of evidence-based laboratory safety management tools for a public health laboratory, Safety Science, Vol. 117, pp. 205-216. DOI: https://doi.org/10.1016/j.ssci.2019.04.003 
Kim, N.K., Rahim, N.F.A., Iranmanesh, M. and Foroughi, B. (2019) The role of the safety climate in the successful implementation of safety management systems, Safety Science, Vol. 118, pp. 48-56. DOI: https://doi.org/10.1016/j.ssci.2019.05.008.

Kim, A.R., Kim, D.Y., Kim, J.S., Lee, H., Sung, J.H. and Yoo, C. (2019) Application of cold intolerance symptom severity questionnaire among vibration-exposed workers as a screening tool for the early detection of hand-arm vibration syndrome: a cross-sectional study, Annals of Occupational and Environmental Medicine, Vol. 31, No. 6. DOI: https://doi.org/10.1186/s40557-019-0284-X

Maeda, S., Taylor, M.D., Anderson, L.C. and McLaughlin, J. Determination of handtransmitted vibration risk on the human, International Journal of Industrial Ergonomics, Vol. 70, pp. 28-37. DOI: https://doi.org/10.1016/j.ergon.2019.01.002.

Martinez, J.G., Gheisari, M. and Alarcón, L.F. (2020) UAV integration in current construction safety planning and monitoring processes: case study of a high-rise building construction project in Chile, Journal of Management in Engineering, Vol. 36, No. 3. DOI: https://doi.org/10.1061/(ASCE)ME.1943-5479.0000761

Nazir, F., Edwards, D.J., Shelbourn, M., Martek, I., Thwala, W.D. and El-Gohary, H. (2020) Comparison of modular and traditional UK housing construction: a bibliometric analysis, Journal of Engineering Design and Technology. DOI: https://doi.org/10.1108/JEDT-05-2020-0193

Notini, L., Mansfield, N.J. and Edwards, D.J. (2008) The importance of powertool consumables on vibration exposure, In: Proceedings of the Ergonomics Society: Health and Well Being of Construction Workers Symposium, Nottingham, UK, 1-3 April 2008. pp. 191-196. ISDN:978-0-415-465755OECD (2016) Health workforce policies in OECD countries: right jobs, right skills, right places, The Organisation for Economic Co-operation and Development (OECD), OECD Health Policy Studies, Paris: OECD Publishing. DOI: https://doi.org/10.1787/9789264239517-en

Oswald, D., Wade, F., Sherratt, F. and Smith, S.D. (2019) Communicating Health and Safety on a Multinational Construction Project: Challenges and Strategies, Journal of Construction Engineering and Management, Vol. 145, No. 4. DOI: https://doi.org/10.1061/(ASCE)CO.1943-7862.0001634

Pain, S.W. (2019) Safety, health and environment auditing: a practical guide, $2^{\text {nd }}$ Ed. CRc Press, Boca Raton, FL. ISBN-13: 978-1-138-55715-4

Palmer, K.T., Griffin, M.J., Syddall, H. Cooper, C. and Coggon, D. (2002) The clinical grading of Raynaud's phenomenon and vibration-induced white finger: relationship 
between finger blanching and difficulties in using the upper limb. International Archives of Occupational and Environmental Health, Vol. 75, pp. 29-36. DOI: https://doi.org/10.1007/s004200100275

Pärn, E. A. and Edwards, D. J. (2017) Conceptualising the FINDD API plug-in: a study of BIM-FM integration. Automation in Construction, 80, pp. 11-21. DOI:10.1016/j.autcon.2017.03.015

Priest, W.C. (1988) Risks, concerns and social legislation: forces that led to the laws on health, safety and the environment, Taylor and Francis, Oxon. ISBN-13: 978-0-36728614-9

Provan, D.J. and Pryor, P. (2019) The emergence of the occupational health and safety profession in Australia, Safety Science, Vol. 117, pp. 428-436. DOI: https://doi.org/10.1016/j.ssci.2019.04.036

Pryor, P., Hale, A. and Hudson, D. (2019) Development of a global framework for OHS professional practice, Safety Science, Vol. 117, pp. 404-416. DOI: https://doi.org/10.1016/j.ssci.2019.04.033

Rashid Z., Shafiq M., Cocca P., Marciano F. and Tayyab A. (2018) Hand arm vibration, grip strength assessment and the prevalence of health disorders among stone crushing workers. In: Goonetilleke R., Karwowski W. (eds) Advances in Physical Ergonomics and Human Factors. AHFE 2017. Advances in Intelligent Systems and Computing, vol 602. Chambridge: Springer. DOI: https://doi.org/10.1007/978-3-319-60825-9_1

Rimell, A. N., Notini, L., Mansfield, N. J., and Edwards, D. J. (2008) Variation between manufacturers' declared vibration emission values and those measured under simulated workplace conditions for a range of hand-held power tools typically found in the construction industry, International Journal of Industrial Ergonomics, Vol. 38, No. 910, pp. 661-675. DOI: https://doi.org/10.1016/j.ergon.2007.10.023

Roberts, C. J., Pärn, E. A., Edwards, D. J. and Aigbavboa, C. (2018) Digitalising asset management: concomitant benefits and persistent challenges. International Journal of Building Pathology and Adaptation, 36(2), pp. 152-173. DOI:10.1108/IJBPA-09-20170036

Stjernbrandt, A., Pettersson, H., Liljelind, I., Nilsson, T. and Wahlström, J. (2019) Raynaud's phenomenon in Northern Sweden: a population-based nested case-control study. Rheumatology International, Vol. 39, pp. 265-275. DOI: https://doi.org/10.1007/s00296-018-4133-y 
Smallman, C. and John, G. (2001) British directors perspectives on the impact of health and safety on corporate performance, Safety Science, Vol. 38, No. 3, pp. 227-239. DOI: https://doi.org/10.1016/S0925-7535(01)00003-0

Spellacy, J., Edwards, D.J., Roberts, C.J., Hayhow, S. and Shelbourn, M. (2020) An investigation into the role of the quantity surveyor in the value management workshop process, Journal of Engineering Design and Technology. DOI: https://doi.org/10.1108/JEDT-07-2020-0289

Sui, Y., Ding, R. and Wang, H. (2018) An integrated management system for occupational health and safety and environment in an operating nuclear power plant in East China and its management information system, Journal of Cleaner Production, Vol. 183, pp. 261-271. DOI: https://doi.org/10.1016/j.jclepro.2018.02.101

US Bureau of Labour Statistics (2020) Injuries, illnesses and fatalities, US Bureau of Labour Statistics, Washington, DC. Available via: https://www.bls.gov/iif/oshwc/cfoi/cftb0330.htm [Accessed June 2020].

Vandenberghe, F. (2015) What's Critical about Critical Realism? Routledge, London. ISBN13: 978-1-138-79857-1

Yin, R. (2009) Cases Study Research: Design and Methods, Sage Publications: London. ISBN: 978-1-4129-6099-1 
Figure 1 - Case company's current vibration process management regime and spans of control

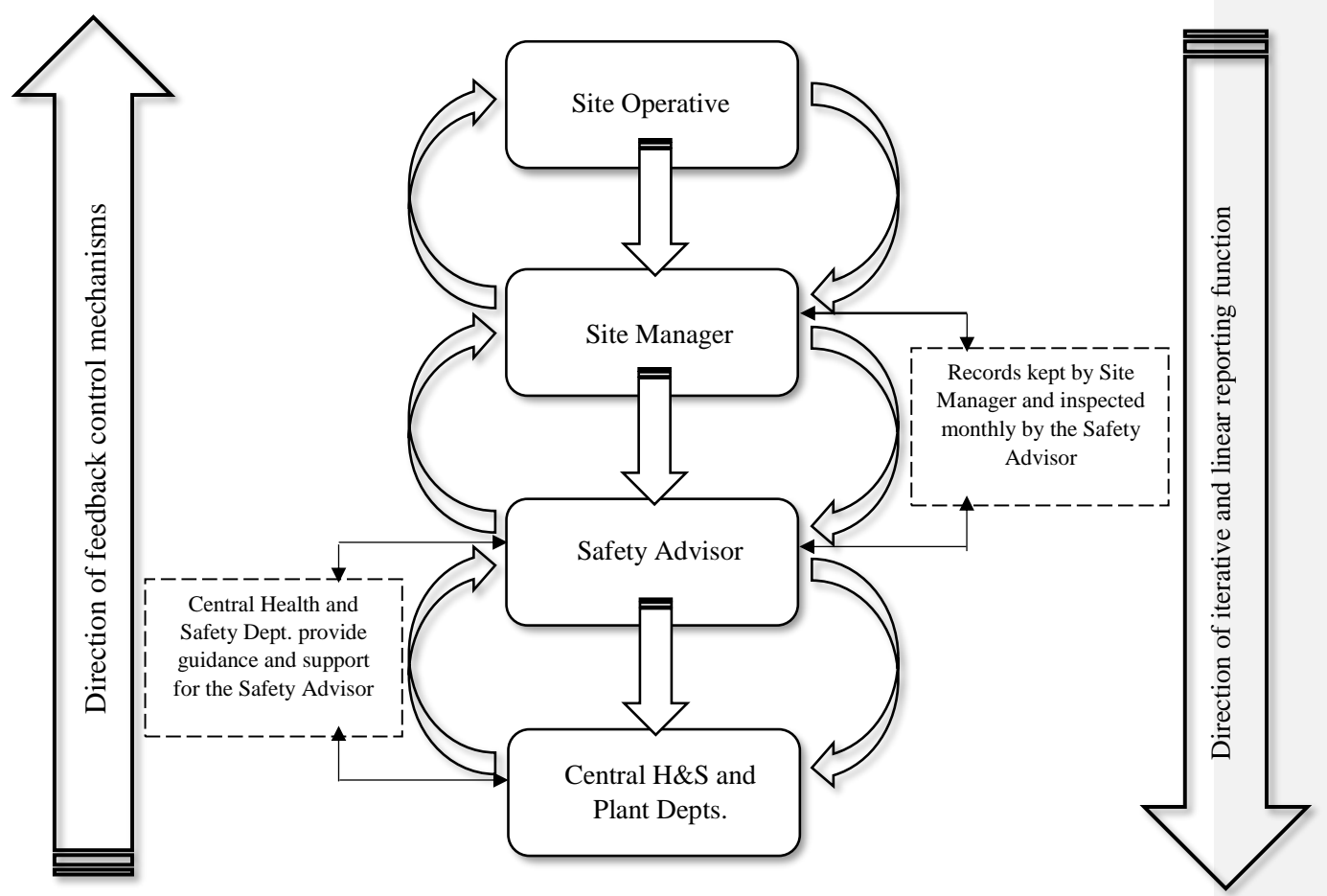


Figure 2 - HAV H\&S strategy framework

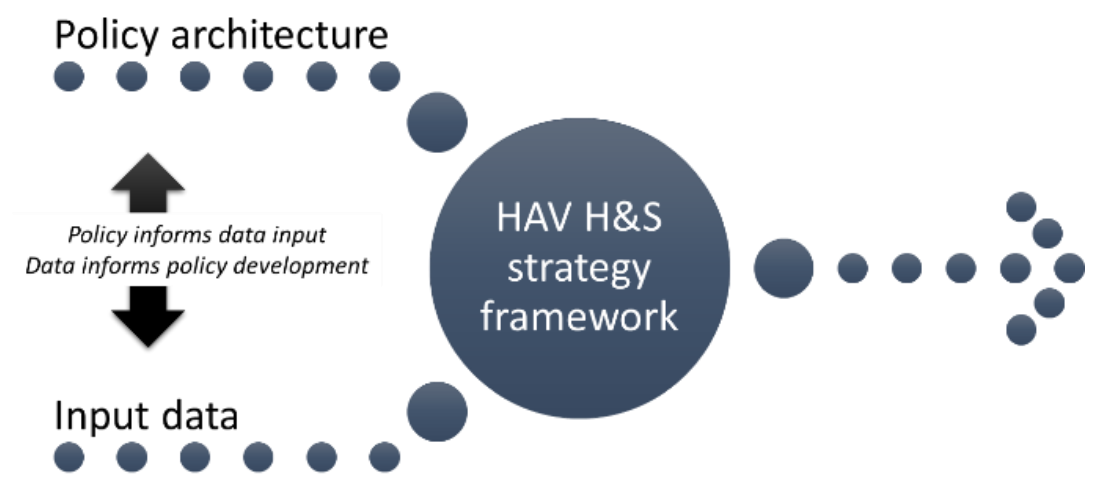


Figure 3 - Theoretical construct: a HAV policy doctrine framework

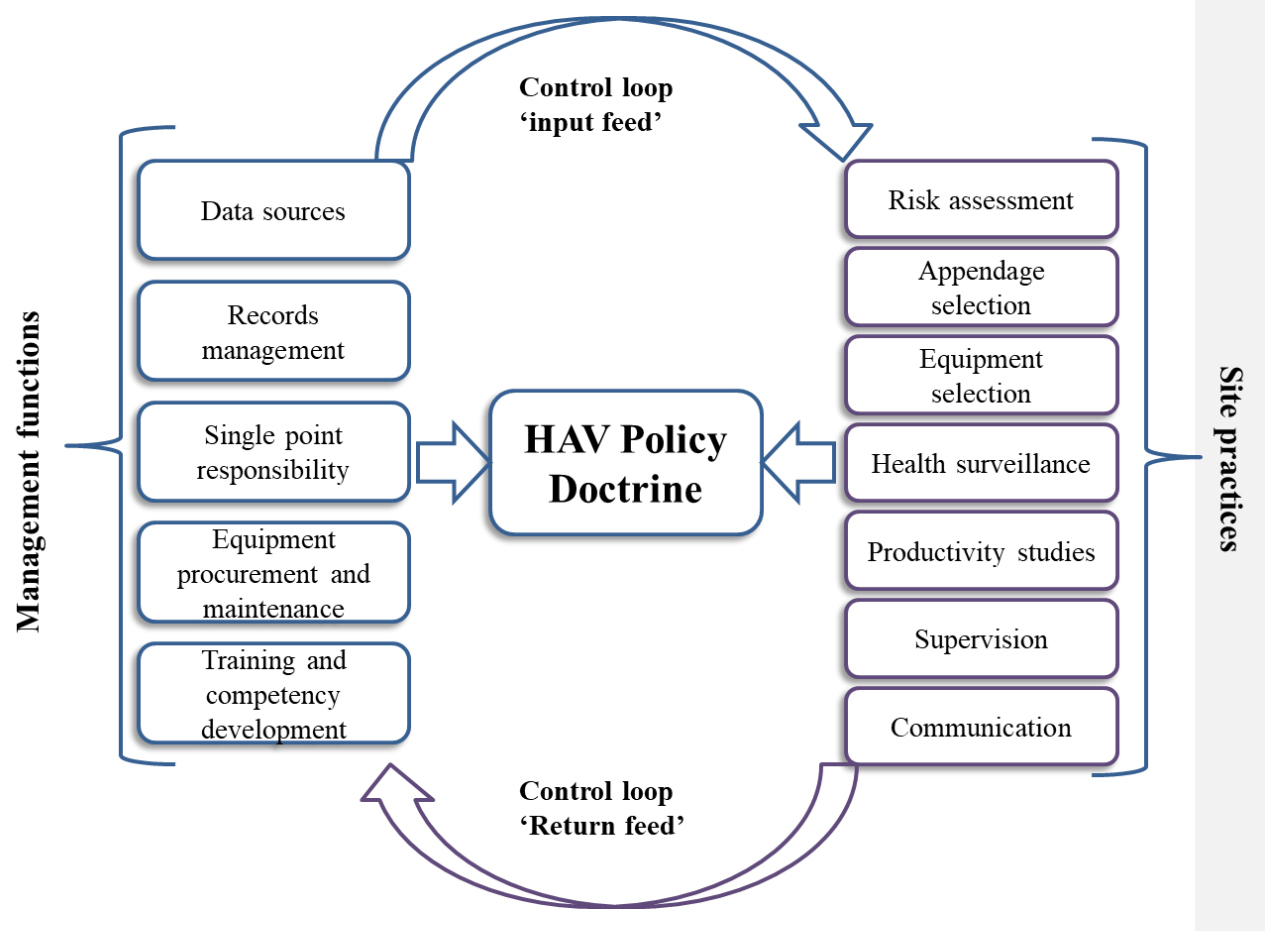


Figure 4 - Field input data procedure schematic

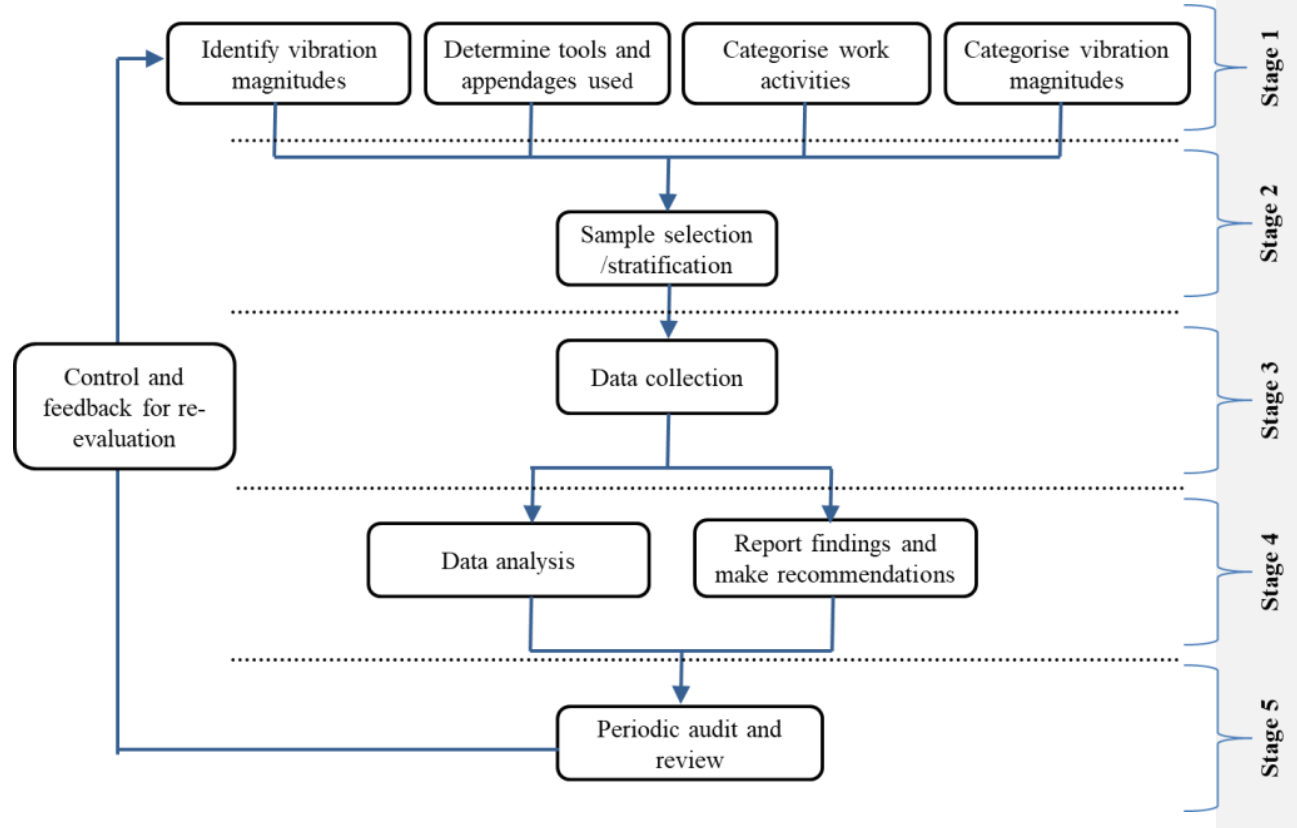

